Proc. of the X Int. Conf. - Ion Implantation and other Applications of Ions and Electrons, Kazimierz Dolny 2014

\title{
Materials Research on Archaeological Objects Using PIXE and Other Non-Invasive Techniques
}

\author{
E.A. Miśta ${ }^{a, *}$, A. Stonert ${ }^{a}$, A. Korman ${ }^{a}$, J.J. Milczarek ${ }^{a}$, I. FiJą-KirejczyK ${ }^{a}$, \\ P. KALBARCZYK ${ }^{b}$ AND A. WiŚNIEWSKA ${ }^{c}$ \\ ${ }^{a}$ National Centre for Nuclear Research, A. Sołtana 7, 05-400 Otwock-Świerk, Poland \\ ${ }^{b}$ Institute of Nuclear Chemistry and Technology, Warsaw, Poland \\ ${ }^{c}$ Antiquity of Southeastern Europe Research Centre, University of Warsaw, Warsaw, Poland
}

\begin{abstract}
An interdisciplinary study of metallic objects from selected archaeological sites in Poland was performed. The aim of the project was to obtain information about the chemical composition and structural changes of the objects. Furthermore, the research results provided information about the technological process which was used to manufacture the artifacts. The materials research had a non- and micro-invasive character which is very important in this type of investigation. The main experimental tools were particle-induced X-ray emission supplemented with nuclear reaction thermal neutron (white beam) radiography, scanning electron microscopy with X-ray energy dispersive analysis, and laser ablation inductively coupled plasma mass spectrometry techniques. The results show that the artifacts were made by a secondary smelting process used in local metallurgy manufactures.
\end{abstract}

DOI: $10.12693 /$ APhysPolA.128.815

PACS: 81.05.Bx, 82.80.Ej, 82.80.Dx, 82.80.Ms, 82.80.Pv

\section{Introduction}

Metallic objects of ancient cultures (dating from 2nd century $\mathrm{BC}$ to 5th century $\mathrm{AD}$ ) were found in many archaeological sites in Poland during the last century and these discoveries are still in progress. The results are focused on materials research techniques applied in the archaeological field. Such a comparison is of unquestionable importance for European cultural heritage. This provides plain information about some aspects of ancient metallurgy processes. Consequently, the use of materials research techniques can answer the questions which are beyond the scope of conventional archeological studies e.g. what kind of metallurgy craft was used, whether the secondary smelting process was used, what is the provenance of the technology and ores.

This study shows the results obtained for the artifacts originating from the archaeological site near Łężany village (located in the North of Poland, Reszel commune). The Łężany site is the cremation rite cemetery of the Dol$1 \mathrm{keim} /$ Kovrovo culture. The site dates from the Late Roman period to the Early Migration period (from second half of 2 nd century till 6th century AD). The materials study was focused on the metal objects originating from collective grave no 31a dated to the second half of the 5th century AD (Fig. 1) [1].

The contents of this grave consisted of belt buckles (3 objects), cicada brooches (4), bracelets (3), clay beads (3) and primitive "brooch" (1). The results of the materials study presented here are focused on the cicada brooches due to their archeological characteristics. Furthermore, cicada brooches found in the Łężany area are

${ }^{*}$ corresponding author; e-mail: ewelina.mista@ncbj.gov.pl

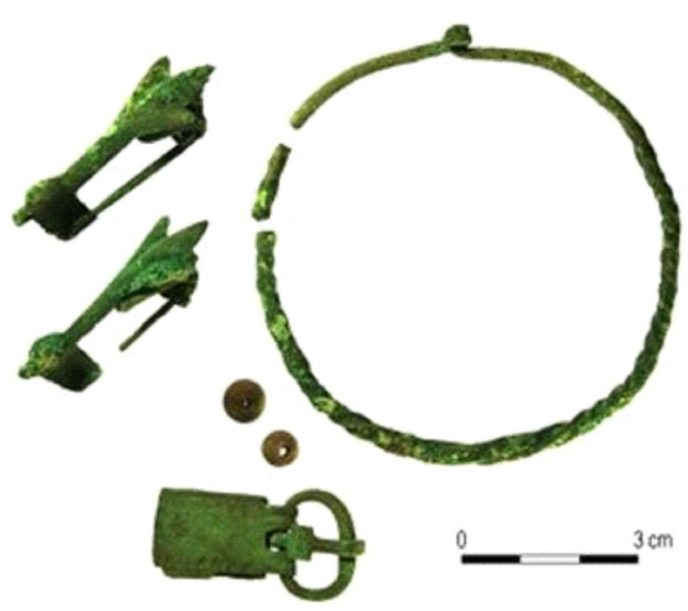

Fig. 1. One of the three groups of objects from grave 31a, Łężany archaeological site.

typical of the Middle Danube River and Black Sea areas. In the Baltic Sea region fibulas of this type were very rarely found $[2,3]$. So far, only four objects; two originating from Lituania, one from Sambian penisula, and two from Poland, have been discovered (excluding those found in Łężany) [2]. However, the data about these Polish brooches are preserved only in the archaeological drawings and photographic documentation. The real objects were lost during the Second World War. Therefore, the archaeological material analogous to the cicadas from Łężany is not available for physicochemical study. The other items from grave 31a represent local crafts (according to the archaeological data [4]), therefore they were considered as reference materials in the study.

\section{Experimental}

Analysis of two types of metal artifacts, cicada brooches and belt buckles, was performed. In the case 
of application of the laser ablation inductively coupled plasma mass spectrometry (LA-ICP-MS) and scanning electron microscopy with X-ray energy dispersive analysis (SEM/EDX) techniques sample preparation was based on mechanical removal of corrosion layers from the surface. Particle-induced X-ray emission (PIXE) and nuclear reaction (NR) methods did not require such a cleaning process. Furthermore, due to the visual features resulting from the technological process used, characteristic points on the objects surface were selected for the analysis. In the case of the belt buckle they were: frame, prong, rivet and fitting and for the cicada brooch - face, spring and pin. The choice of sampling sites was made based on the hypothesis that these parts were prepared separately from different types of metal alloys $[5,6]$.

The qualitative elemental composition of the ancient alloys was determined by the PIXE method. The PIXE spectra were collected for all sampling points. A $1 \mathrm{MeV}$ proton beam from a Van de Graff accelerator was used as a source for material atoms excitation. The $\mathrm{X}$-rays were registered with a $\mathrm{Si}(\mathrm{Li}) \mathrm{X}$-ray $250 \mathrm{eV}$ resolution detector (National Centre for Nuclear Research, Poland). To determine the alloys, the quantitative elemental composition SEM/EDX (Zeiss Poland, EVO MA 10 Scanning Electron Microscope with EDAX spectrometer) and LA-ICP-MS (Perkin Elmer SCIEX, USA, ELAN 9000 spectrometer) [7] techniques were used. Furthermore, to visualize the structural and material differences neutron radiography was applied (the source of the neutron beam was the MARIA research reactor in Świerk, Poland) $[8,9]$.

\section{Results and discussion}

The NR 2 Dimages were registered for all objects on different sides in order to assess progress of structural degradation and material modification. Figure 2 shows the examples of the obtained results.

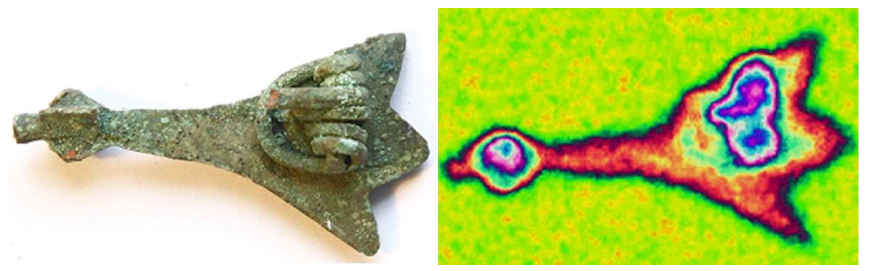

Fig. 2. Real and NR (artificial colors) images registered for the cicada brooch, front view (of the needle site).

The NR study provided the information about different structural compositions of the objects. The material between belt buckle fittings visible in the NR images was found to be organic. These are the remains of preserved organic, probably leather, part of the belt. The NR spectra of the brooches clearly show the thickness differences in the metal alloy structure caused by the natural shape and corrosion layer of the artifacts.

The PIXE spectra were registered for all objects considering the supposed specific origin of the parts (sampling points) $[10,11]$. Figure 3 depicts an example of

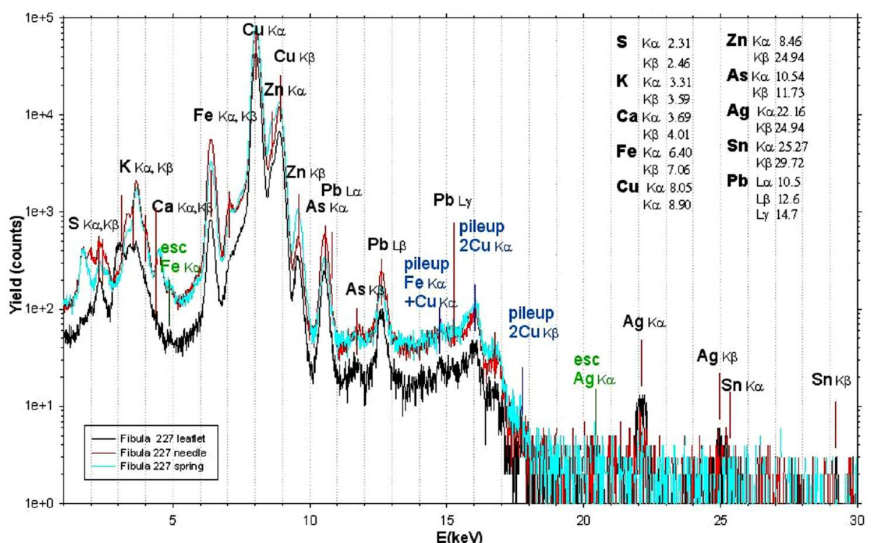

Fig. 3. PIXE spectra measured for cicada brooch no 227, for each part: face (black spectra), pin (red spectra), and spring (blue spectra).

the registered spectra. Due to the fact that the brooch has not yet undergone the conservation process and the sampling was done without preliminary sample preparation, the low energy part of the spectra (Fig. 3) contains peaks corresponding to soil contamination and corrosion elements. Potassium, calcium and sulfur were detected. The results presented in Fig. 3 clearly show that the studied elements of the brooch are composed of brass with some traces of lead (galena ores), tin and iron. These trace elements could originate from typical geological ores. Somewhat surprisingly signals from silver and arsenic were also observed. Silver ores coexist with arsenic and lead but not with tin [12]. Silver is also present as traces (up to $1 \mathrm{wt} \%$ ) in copper and zinc deposits (British Geological Survey [13]). However, in the registered spectra the silver signal has a significant intensity which does not correlate with natural geological ore abundance of this element. This fact could indicate the use of secondary smelting technology. Further, all technological parts of the brooch are made from the compounds originating from the same source. Consequently, they could be produced by the same workshop.

Generally, the artifact qualitative elemental composition (determined by the PIXE) is the same for all of the objects. The shape of the PIXE spectra measured for the belt buckles is similar to that of the cicada brooches. This clearly indicates that the studied objects were produced with the same process.

The LA-ICP-MS quantitative elemental analysis confirmed the results obtained by PIXE. Figure 4 presents the results of spectrometric analysis for all types of studied artifacts. The diagram does not include the results obtained for copper as a main alloy composite. The copper content was determined in the range 200-600 ppm.

SEM/EDX analysis (Fig. 5) with mapping tests (Fig. 6) show that the alloys are inhomogeneous. The EDX analysis was performed for all artifacts. For each object (for repetitive sampling point, cf. Fig. 5), the obtained EDX results revealed a different elemental composition for each of the three sampling points. Most probably this is due to the heterogeneous structure of 


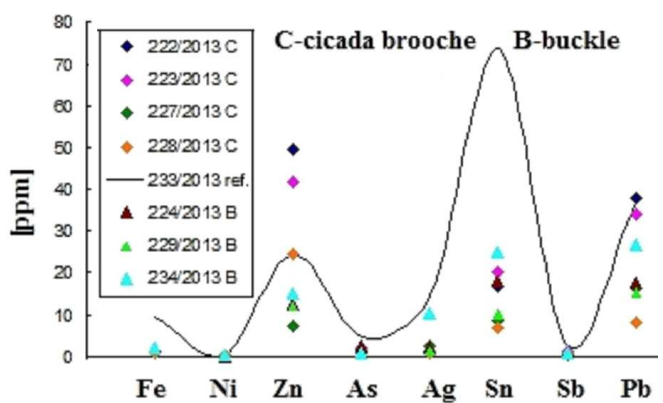

Fig. 4. Average elemental composition [in ppm] of the cicada brooches (C), belt buckles (B), and reference fibulae (ref.) obtained by LA-ICP-MS, measurement error $5 \%$.

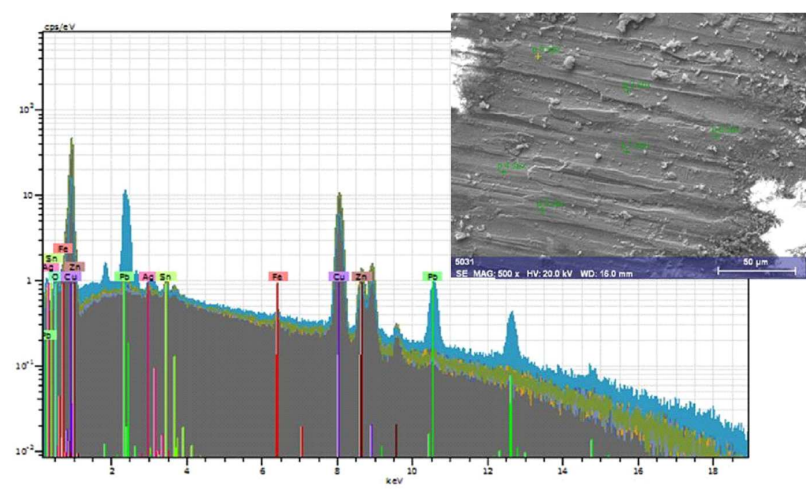

Fig. 5. EDX spectra (three times sampling) with surface SEM image of sampling area, belt buckle no 229 .

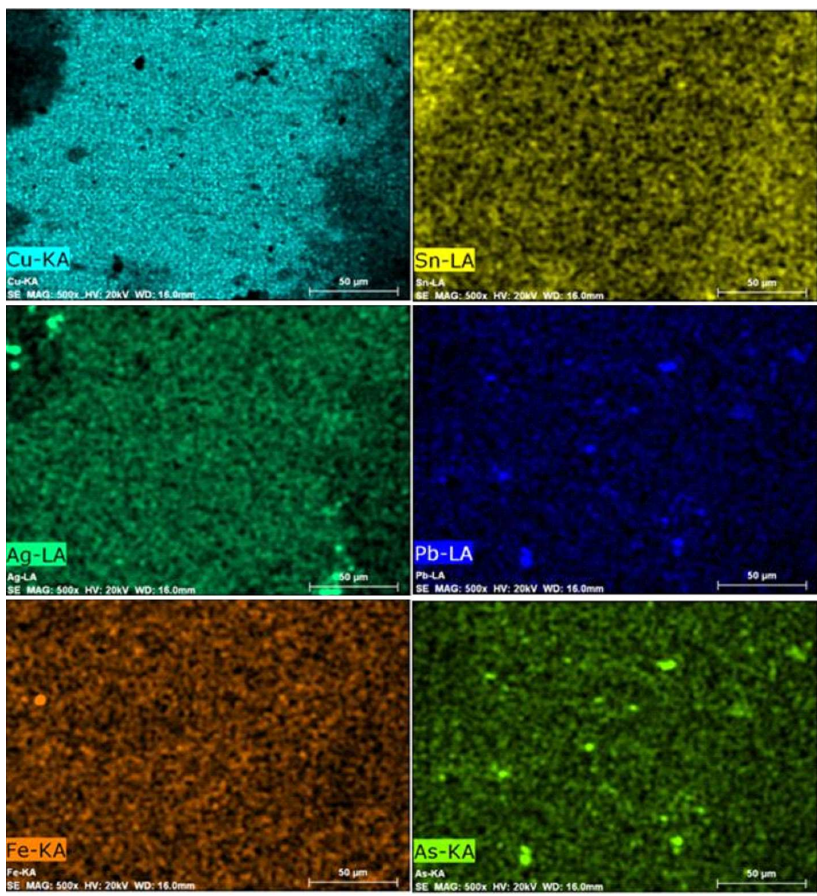

Fig. 6. Results of EDX mapping, belt buckle no 229 after surface mechanical cleaning. the brass alloy [12]. Furthermore, the EDX spectrum with the maximum silver signal intensity (the blue one in Fig. 5) is connected with the presence of lead. Due to the presence of silver deposits in galena ores, this could indicate the use of silver alloy components in the secondary smelting process.

\section{Conclusions}

The research reported here confirmed the usefulness of non and micro-invasive physicochemical techniques in archaeology. New information about the ancient metallurgical techniques used to prepare selected objects from the Łężany site was obtained. Cicada brooches were made using the same technology as belt buckles. Furthermore, the secondary smelting process was used. Selected parts of each type of artifact were made of the same raw materials, the elemental composition of alloys is similar. This indicates that local metallurgy manufacture was used to prepare the artifacts. Hence, the cicada brooches originate from local manufacture not from the South. The research is in progress. Current archaeological excavations yielded other artifacts which together with the environmental samples are being studied.

\section{References}

[1] E.A. Miśta, P. Kalbarczyk, in: Lęzany - the Cemetery of the Roman Period and the Migration Period in the Mragowo Lake District, Research in the Season 2013, Ed. A. Wiśniewska, Dajna Foundation, Warsaw 2014, p. 131.

[2] A. Wiśniewska, Cicada brooches from Łężany. New evidence links the Balt milieu with the south in the Migration Period, in: Neue Studien zur Sachsenforschung, Germany (in press).

[3] M. Mączyńska, in: Balts and Their Neighbours, Eds.: A. Bitner-Wróblewska, G. Iwanowska, Warszawa 2009, p. 397 (in Polish).

[4] Eęzany - the Cemetery of the Roman Period and the Migration Period in the Mragowo Lake District, Research in the Season 2013, Ed. A. Wiśniewska, Dajna Foundation, Warsaw 2014.

[5] R.J. Forbres, Studies in Ancient Technology, Vol. VII, VIII, IX, E.J. Brill, Leiden 1963.

[6] R.F. Tylecote, A History of Metallurgy, 2nd ed., The Institute of Materials, MANEY 1992.

[7] D. Walaszek, Ph.D. Thesis, Warsaw/Dubendorf, 2012.

[8] E. Deschler-Erb, E.H. Lehmann, L. Pernet, P. Vontobel, S. Hartmann, Archaeometry 46, 647 (2004).

[9] A. Czachor, Abd El-Ghany El Abd, J.J. Milczarek, Acta Phys. Pol. A 102, 245 (2002).

[10] Z. Smit, J. Istenuc, T. Knific, Nucl. Instrum. Methods Phys. Res. B 226, 2329 (2008).

[11] M. Uda, G. Demortier, I. Nakai, X-ray for Archaeology, Springer, Netherlands 2005.

[12] D.A. Scott, Metallography and Microstructure of Ancient and Historic Metals, The Getty Conservation Institute, The J. Paul Getty Museum, Singapore 1991.

[13] British Geological Survey, Zinc ore and mines (05.09.2014). 